\title{
Diversificación, precios y calidad de las exportaciones españolas: una comparación a nivel europeo*
}

\author{
Esther Gordo Mora \\ Patrocinio Tello Casas \\ Banco de España
}

\begin{abstract}
Resumen
En este trabajo se trata de indagar en los factores que subyacen a la evolución de las cuotas de exportación de bienes de España en los años recientes, empleando la información de comercio exterior a un nivel muy elevado de desagregación. En particular, a partir de la información disponible en la base de datos COMTRADE de Naciones Unidas y siguiendo la metodología desarrollada por Hummels y Klenow (2005). Se trata de analizar el papel que ha jugado la diversificación por productos y mercados en los resultados comerciales de España (margen extensivo), la evolución de la intensidad exportadora (margen intensivo) y la importancia que tienen las estrategias de diferenciación en segmentos de calidad de las exportaciones (margen cualitativo). Los resultados se comparan con los observados en Alemania, Francia e Italia.
\end{abstract}

Palabras clave: variedad, cantidad y calidad, márgenes extensivo e intensivo.

Clasificación JEL: F1, F14, F43.

Abstract

This paper studies the role play by variety and quality of trade in explaining differences in export market shares developments across the main euro-area countries since 2000 to 2009. Following the methodology proposed by Hummels and Klenow (2005), and using a very detailed data on export flows (COMTRADE), we estimate the extensive margin (the number of products or varieties), the intensive margin (the quantity exported of each goods) and the qualitative margin (the quality of products) of Spanish, German, French and Italian exports. This allows us to assess wheter the horizontal or vertical product differentiation help to explain the relative good behavior of Spanish exports since 2000.

Keywords: variety, quantity and quality, extensive and intensive margins.

JEL classification: F1, F14, F43.

\section{Introducción}

Uno de los rasgos que ha caracterizado la evolución del comercio exterior de España en los últimos años ha sido la resistencia que ha mostrado nuestra cuota de exportación en los mercados mundiales a pesar del creciente protagonismo de los países emergentes, que han incrementado notablemente su participación en los flu-

* Los autores agradecen la asistencia técnica prestada por Antonio Rodríguez Caloca, del Servicio de Estudios del Banco de España. 
jos internacionales en detrimento de la de los países desarrollados. Este resultado contrasta con lo observado en otros países de nuestro entorno que han registrado pérdidas más o menos generalizadas de cuotas, con la notable excepción de lo sucedido en Alemania, que también ha logrado mantener su cuota de exportación. Como se aprecia en el Gráfico 1, mientras que la participación de Alemania y de España en el comercio mundial prácticamente se estabilizó, en términos nominales, en 2010 en niveles cercanos a los observados a comienzos de la década (un 8,4 por 100 y un 1,6 por 100, respectivamente), en Francia y en Italia las cuotas de exportación se redujeron hasta el 3,4 por 100 y el 2,9 por 100 del comercio mundial de bienes, respectivamente.

Justificar el comportamiento relativamente favorable de las cuotas de exportación de bienes de España supone un reto para los analistas del comercio exterior. Si bien es cierto que la cuota se ha estabilizado en niveles reducidos, inferiores a la participación de la economía en el PIB mundial ${ }^{1}$, numerosos trabajos han puesto de manifiesto algunas debilidades que habrían llevado a esperar un resultado más adverso de las exportaciones españolas en un entorno de competencia creciente. En particular, desde la perspectiva de nuestra especialización sectorial, se puede mencionar la elevada participación relativa en las exportaciones españolas de los sectores de tecnología baja, que la hacía especialmente vulnerable a las presiones competitivas de los competidores de bajo coste, y la excesiva dependencia del sector de automóvil, que representa en torno al 20 por 100 del total de las exportaciones y que en los últimos años ha estado expuesto a un proceso de reasignación geográfica de la actividad. La composición geográfica también revela vulnerabilidades, al estar las exportaciones muy concentradas en los mercados europeos y tener una reducida presencia en los mercados emergentes, con mayor potencial de crecimiento. $\mathrm{Y}$ a todo ello cabe añadir la pérdida de competitividad medida en términos de precios y costes que ha registrado la economía española desde la entrada en la UEM (véase García y Tello, 2011).

Algunos analistas que tratan de explicar esta aparente paradoja, recurren a datos microeconómicos para analizar las características de las empresas exportadoras españolas, en relación con los países de nuestro entorno. En esta línea, Antràs, Segura y Rodríguez (2010) enfatizan la importancia de la heterogeneidad empresarial para justificar el buen comportamiento del sector exterior español en términos de mantenimiento de cuotas de mercado internacionales. Según estos autores, la empresas exportadoras españolas están compuestas por un número muy abundante de empresas pequeñas, menos productivas que las empresas de igual tamaño de los países de nuestro entorno, y un número relativamente reducido de empresas grandes, que realizan un porcentaje muy elevado de las exportaciones y que no sólo son más productivas que las empresas no exportadoras de tamaño equivalente, sino que

${ }^{1}$ Este hecho contrasta con lo que sucede en las economías de mayor tamaño de nuestro entorno. En términos reales, el peso de España en el PIB mundial se sitúa próximo al 2,5 por 100 y el de las exportaciones en torno al 2 por 100, en comparación con el 4 por 100 y el 7,2 por 100, respectivamente, de Alemania; el 3 por 100 y el 4,3 por 100 de Francia y el 2,5 por 100 y el 3,4 por 100 de Italia. 


\section{GRÁFICO 1 \\ CUOTAS DE EXPORTACIÓN DE BIENES EN EL MUNDO}

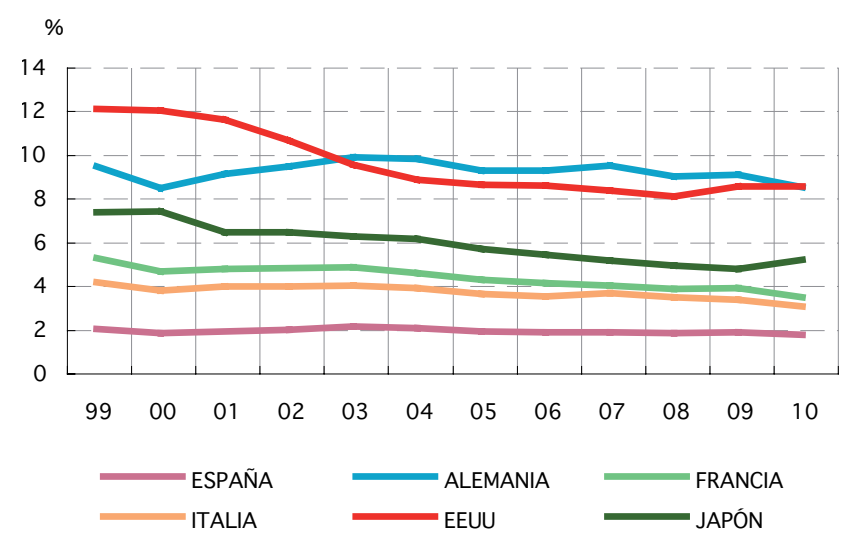

Índice $1999=100$

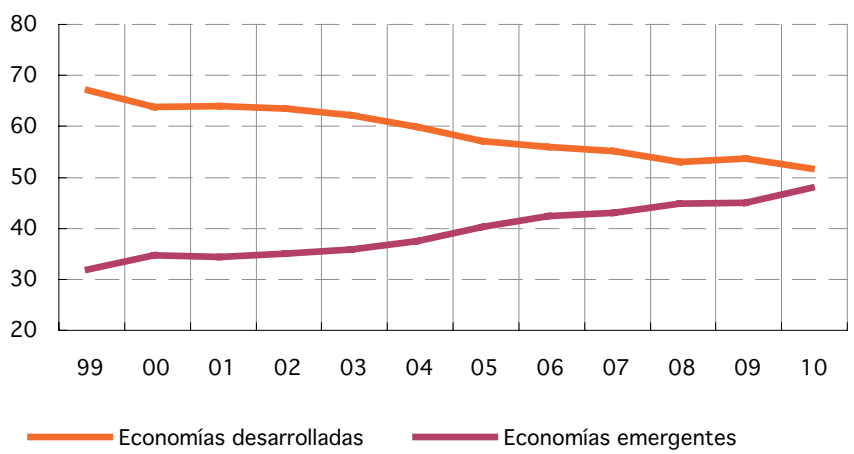

FUENTE: FMI, CPB (Netherlands Bureau for Economic Policy Analysis) y BCE.

también presentan unos niveles y una evolución de la productividad superiores a los registrados por este tipo de empresas en Alemania, Francia o Italia. Esta evidencia se encuentra en línea con la obtenida a partir de la reciente encuesta EFIGE (Navaretti et al., 2011), que pone de manifiesto que el grado de internacionalización de las economías europeas se explica en buena medida por las características de sus empresas y, en mucha menor medida, por el país de residencia de las mismas. Lamentablemente la información microeconómica disponible para la economía española no tiene todavía la riqueza suficiente como para obtener resultados concluyentes en este sentido. Rodríguez (2008), Martín y Rodríguez (2009) y Martín et al. (2009) ofrecen evidencia sobre las características de las empresas exportadoras españolas.

En este trabajo se pretende indagar en la evolución reciente de las exportaciones 
españolas desde una perspectiva distinta a la microeconómica o a la que se deriva del enfoque sectorial. En concreto, a partir del análisis de las cifras de comercio disponibles con el máximo nivel de desagregación por productos y mercados, se trata de estudiar la capacidad que ha mostrado la economía española para diversificar las ventas al exterior por productos y mercados de destino y la importancia de las estrategias de diferenciación de la producción en segmentos de calidad.

El trabajo se enmarca, por tanto, en la literatura empírica desarrollada a lo largo de los últimos diez años, que trata de explicar las diferencias en los niveles o en las cuotas de exportación de las distintas economías en función de la importancia relativa de la diversificación o número de productos o categorías de producto que produce cada país (lo que se denomina margen extensivo) y de la intensidad exportadora o del valor exportado de cada producto o categoría (margen intensivo), según la metodología desarrollada por Hummels y Klenow (2005). El margen intensivo suele descomponerse, a su vez, en dos elementos que reflejan la aportación de la cantidad exportada de cada producto hacia un mercado concreto y su precio de exportación que, bajo determinadas condiciones, guarda una relación con la estrategia de diferenciación en segmentos de calidad de la economía.

Esta literatura, a partir de los estudios realizados con datos a un nivel de desagregación por productos y mercados muy elevado, ha permitido profundizar en el análisis de los resultados comerciales. Una de sus principales conclusiones es que, en general, los países no se especializan en la producción de distintas industrias, sino en diferentes segmentos de calidad de un mismo producto, lo que ha llevado a revisar algunas de las conclusiones sobre las presiones competitivas a que se enfrenta cada país procedentes de las economías emergentes. Por ejemplo, Fontagné et al. (2008) encuentran que incluso al máximo nivel de desagregación posible, de todos los potenciales pares de productos exportados-mercado de destino, China exportaba en 335.720 de ellos en 2004, solo ligeramente por debajo de los 352.835 de Alemania. Este resultado podría llevar a inferir que los productos alemanes se enfrentan a un grado de competencia muy intenso por parte de China. No obstante, los autores revelan que ambos países se especializan en la producción de segmentos de calidad muy distintos, dentro de cada producto o categoría, lo que sugiere conclusiones muy distintas sobre la exposición a la competencia de países emergentes (Khandewal, 2010).

Para la economía española la evidencia disponible desde este enfoque es relativamente escasa. Uno de los primeros trabajos es el de Cuadras y Puig (2008), que empleando las cifras de exportaciones correspondientes al año 2005, encuentran que ambos márgenes, extensivo e intensivo, juegan un papel relevante a la hora de explicar el menor nivel de las exportaciones españolas. Según los resultados de estos autores, tanto la diversificación de las exportaciones por productos y mercados (margen extensivo), como la calidad de los productos que se venden (margen cualitativo) es inferior a lo que cabría esperar dado el tamaño y el grado de desarrollo de la economía española.

El objetivo de este artículo es profundizar en la evidencia sobre la intensidad 
exportadora a nivel de productos y mercados (margen intensivo), la variedad de las exportaciones (margen extensivo) y analizar los segmentos de calidad que predominan en los intercambios comerciales de España con el resto del mundo (margen cualitativo). Para ello se emplean las cifras disponibles en la base de datos COMTRADE de Naciones Unidas, a un nivel de desagregación por productos muy elevado (6 dígitos del Sistema Armonizado -Harmonized System, HS en terminología inglesa-, que comprende en torno a 5.100 productos). A diferencia de la mayoría de los trabajos realizados que utilizan la información relativa a un único año, aquí se emplean las cifras disponibles para el periodo 2000-2009, lo que permite detectar los posibles cambios en la calidad y variedad de los bienes exportados en ese período y analizar los distintos comportamientos o estrategias seguidos en un entorno en que los países emergentes han ido desplegando su potencial exportador. En cuanto al conjunto de países considerados en este análisis, de momento solo se ha considerado la información relativa a España, Alemania, Francia e Italia, además del total mundial. Es cierto que los países elegidos constituyen las economías de mayor tamaño de la UE, pero como se verá posteriormente el reducido número de países considerado limita el análisis econométrico de los determinantes de estos márgenes que se ha podido realizar ${ }^{2}$.

Cabe destacar que la variedad y la calidad son conceptos complejos y las aproximaciones que se emplean para cuantificarlos deben interpretarse con las debidas cautelas. Con todo, nuestros resultados revelan que la evolución comparativamente favorable de la cuota de exportación de España responde en buena medida al mayor incremento del grado de diversificación de las ventas por productos y mercados, que ha sido más intensa en los mercados asiáticos y en las economías menos desarrolladas. La intensidad exportadora a nivel de producto-país se ha mantenido relativamente estable durante el período analizado (2000-2009), en contraste con el retroceso que se aprecia en otras economías de nuestro entorno como Francia o Italia. Con todo, su nivel sigue siendo reducido. En cuanto a los precios de las exportaciones, España mantiene, en media, unos niveles de precios similares a los registrados en el promedio mundial, mientras que Alemania, Francia o Italia registran precios relativos elevados, en comparación con el resto del mundo, que podrían ser indicativos de una mayor importancia de la especialización en segmentos de calidad más elevada en estas economías. Los factores que subyacen a estos desarrollos se analizarán con más detalle en un futuro, cuando se disponga de una base de datos con mayor número de países.

El artículo se organiza como sigue. En la siguiente sección se describe la evidencia teórica y empírica existente a nivel internacional sobre el papel de la variedad y calidad en la evolución de las exportaciones. Posteriormente, se describe con detalle la base de datos y la metodología empleada. En el apartado 4 se comentan los prin-

\footnotetext{
2 En la actualidad se está llevando a cabo una ampliación de la base de datos considerando un número mayor de países exportadores, lo que permitirá estudiar con más detalle los determinantes de la variedad y de la intensidad exportadora, profundizando en el análisis de la calidad relativa de los productos exportados.
} 
cipales resultados obtenidos para España, en comparación con el resto de las economías consideradas, y se comentan las diferencias estimadas y su posible incidencia en la diferente evolución de las cuotas de exportación de bienes observada. En el apartado 5, se presenta una estimación que trata de relacionar las diferencias en los precios de exportación de España a los diferentes mercados de destino, con las características de esos mercados. Finalmente se resumen las principales conclusiones.

\section{El papel de la calidad y la diversificación por producto y mercados en la evolución de las exportaciones: teoría y evidencia empírica}

La disponibilidad de información de comercio internacional de bienes con un elevado grado de desagregación a nivel de producto-país de destino y, más recientemente, a nivel de empresa-producto-país, y la disponibilidad de paquetes informáticos para el tratamiento de grandes bases de datos, ha permitido realizar grandes avances en el conocimiento de los flujos comerciales con una perspectiva distinta de la que habitualmente se obtiene a nivel de rama o sector y de mercado de destino.

Entre los artículos más influyentes en esta literatura cabe destacar los de Schott (2004) y Hummels y Klenow (2005), que, analizando los flujos comerciales con un nivel de desagregación muy elevado, revelan que las economías más grandes y más desarrolladas no sólo presentan una mayor intensidad exportadora (margen intensivo), sino que también tienden a exportar un número mayor de variedades (margen extensivo). Por ejemplo, Hummels y Klenow (2005) $)^{3}$ encuentran que aproximadamente un 60 por 100 de las mayores cuotas de exportación de las economías desarrolladas se explica por la mayor contribución del margen extensivo (diversificación por productos y mercados), en tanto que el 40 por 100 restante se debe a una mayor intensidad exportadora (margen intensivo).

Por su parte, Schott (2004) utiliza datos de las importaciones de EEUU con un nivel de desagregación por productos y países de origen muy elevado y encuentra una elevada heterogeneidad en los precios de importación de cada producto, dependiendo del mercado de origen. Al analizar los factores que pueden explicar esa heterogeneidad encuentra una relación positiva entre el nivel de los precios de cada bien -aproximado por los Índices de Valor Unitario, IVU- y el grado de desarrollo y la dotación de capital físico y tecnológico del país exportador.

La existencia de diferencias elevadas en los precios de exportación de un mismo producto en el mismo mercado se confirma en otros trabajos posteriores como el de Fontagné et al. (2008), cuyos resultados revelan que en el año 2004 los IVU de las exportaciones de EE.UU. fueron, en media, en torno a 1,55 veces superiores a los IVU de India o 2,44 a los de China, calculados considerando el mismo producto y el mismo mercado de destino. Además, según estos autores, las diferencias han sido

${ }^{3}$ Estos autores emplean datos del año 1995 para 126 países exportadores, considerando 59 países de destino. 
muy persistentes desde mediados de los noventa. La persistencia de niveles de precios relativos de exportación comparativamente elevados en algunas economías suelen asociarse con la existencia de diferenciación vertical en términos de calidad de los productos exportados, y de ahí se derivan conclusiones muy distintas sobre el grado de competencia que ejercen las economías emergentes en los distintos segmentos de mercado de las que se obtienen al comparar la estructura de especialización con las cifras disponibles a nivel sectorial ${ }^{4}$.

La evidencia obtenida a este nivel de detalle resulta difícil de conciliar con los postulados de la teoría tradicional de comercio y con la denominada nueva teoría del comercio internacional. En concreto, la teoría más ortodoxa justifica la existencia del comercio por la abundancia relativa de factores de producción, que son la fuente de las ventajas comparativas de cada país. De acuerdo con esta teoría, desarrollada en un marco de competencia perfecta, cada país se especializaría en la producción de aquellos bienes que utilizan intensivamente el factor de producción en el que posee abundancia relativa y que produce con menores precios relativos («modelo Hecksher-Ohlin»). El comercio tiene lugar, por tanto, en el margen intensivo ya que el país se especializa en un conjunto limitado de productos que produce con ventajas de costes y, por tanto, con menores precios relativos.

Por su parte, la nueva teoría del comercio internacional, desarrollada en un marco de competencia imperfecta, incorpora dos supuestos que se observan fácilmente en la realidad, la existencia de economías de escala internas a la empresa y la preferencia del consumidor por la variedad, y que permiten justificar que cada país se especialice en la producción de un número determinado de variedades dentro de una misma industria (Krugman, 1979, 1980). A diferencia de lo que sucede en el modelo más tradicional, los intercambios comerciales no se producen entre distintas industrias, sino que se intercambian variedades dentro de la misma industria (comercio intra-industrial). De acuerdo con estos modelos de diferenciación horizontal, será el margen extensivo el que domine en los intercambios comerciales.

Pero ninguna de estas dos teorías puede explicar que un país importe (o exporte) un mismo producto, a precios que difieren significativamente en función de las características del mercado de origen (o de destino).

La existencia de diferencias significativas en los niveles de precios de un mismo producto (o variedad) sólo es posible en los modelos de comercio que admiten la diferenciación vertical de la producción (Grossman y Helpman, 1991, y Sutton, 1986). De acuerdo con estos modelos los países más desarrollados, con mayor capacidad tecnológica y una mejor dotación de capital humano exportarán variedades de mayor calidad, por las que los consumidores están dispuestos a pagar un precio superior e introducirán nuevas variedades cualitativamente superiores para hacer frente a la competencia que pueden ejercer los países menos desarrollados a través

${ }^{4}$ BALDWIN e ITO (2008) estiman que algo más del 90 por 100 de los productos que exportan los grandes países de la UE compiten en calidad, frente al 85 por 100 en el caso de EEUU, el 82 por 100 de Japón y el 55,5 por 100 de China. 
de la imitación de sus técnicas o de las características de su producción, con una mano de obra más barata. Las diferencias en la dotación de factores vuelven a emerger, por tanto, como los determinantes fundamentales de las relaciones comerciales, pero para justificar ahora la especialización de los distintos países en diferentes segmentos de calidad dentro de cada producto, en lugar de la especialización interindustrial que se derivaba de la teoría más ortodoxa ${ }^{5}$.

De las distintas teorías se desprenden algunos de los determinantes de la magnitud de los márgenes extensivo, intensivo y cualitativo. La literatura empírica confirma que los países de mayor tamaño tenderán a mostrar mayores exportaciones (margen intensivo) y también una mayor diversificación de su estructura de exportaciones (margen extensivo), ya que el tamaño del mercado doméstico le permitirá aprovechar las economías de escala en la producción de un espectro más amplio de productos. Asimismo, dentro de cada producto, los países con mayores dotaciones de capital físico y tecnológico y una mano de obra más cualificada mostrarán, en general, una especialización en los segmentos de calidad superior y, por tanto, mayores niveles de sus precios de exportación, bajo el supuesto de que la calidad se refleja, en general, en los precios. Por el contrario, los países de menor tamaño con menor nivel de desarrollo tenderán a exportar menos productos o categorías que están, además, situados, en general, entre los segmentos de calidad inferior ${ }^{6}$.

En el caso concreto de los precios de exportación la evidencia empírica revela que, además de las características de los países exportadores, existen otros factores relacionados con la demanda, esto es, con las características de los mercados de destino que influyen también sobre los resultados. Así, por ejemplo, Hallack (2006) utilizando datos a nivel sectorial de comercio bilateral entre 60 países, encuentra que las naciones más ricas tienden a importar más de los socios comerciales que producen bienes de mayor calidad. La distancia entre países reduce el margen extensivo e intensivo, aunque aumenta el precio (a países más distantes se venden productos de mayor calidad). Esta relación positiva entre distancia y precio, que también es

${ }^{5}$ La denominada «nueva nueva teoría del comercio internacional» que añade la dimensión empresarial al análisis de los determinantes del comercio también da cabida a la existencia de diferencias de precios entre las distintas variedades de un mismo producto. Así, por ejemplo VERHOOGEN (2008) o BALDWIN y HARRIGAN (2011) amplían el modelo seminal de heterogeneidad empresarial de MELITZ (2003) incorporando diferencias en la calidad de los productos y en las preferencias de los consumidores. BASTOS y SILVA (2010), con datos de empresas exportadoras portuguesas, encuentran que las empresas exportadoras más productivas tienden a vender mayores cantidades de cada producto y a mayores precios. Además, los precios de exoprtación aumentan con la distancia y riqueza del país destino de la venta. Lamentablemente para España la información sobre los flujos comerciales a nivel de empresa tienen un carácter confidencial, lo que dificulta analizar con detalle las características de las empresas exportadoras.

6 VAN HOVE (2007) analiza el papel de la variedad y calidad en el comercio intra-UE en el año 2006 y, al igual que HUMMELS y KLENOW (2005), encuentra que los países grandes de la UE exportan un mayor número de variedades y también un mayor valor de cada una de ellas que las economías más pequeñas. No obstante, las venden a un menor precio -ya que la grandes se benefician de economías de escala en la producción-. En cambio, los países con mayores niveles de PIB per cápita venden sus bienes a precios superiores. 
encontrada por Baldwin y Harrigan (2011), podría explicarse porque solo las empresas más productivas, que producen bienes de mayor calidad pueden cubrir los elevados costes de entrada que conlleva la implantación en los mercados más alejados geográficamente o culturalmente; también es posible explicar estas diferencias en los niveles de precios porque dentro de una misma empresa la estrategia de diferenciación de precios difiere según las características del mercado de destino.

A continuación, tras describir la base de datos que se emplea en este trabajo, se comentan los resultados que se obtienen para el margen extensivo, intensivo y cualitativo estimado para la economía española, en comparación con los calculados para Alemania, Francia e Italia.

\section{Base de datos y metodología}

Los datos que se emplean en este trabajo proceden de la base de datos COMTRADE de Naciones Unidas que proporciona información de las exportaciones de bienes, tanto en términos nominales como en cantidades, a un nivel de desagregación por productos muy elevado, a seis dígitos según el Sistema Armonizado del comercio internacional ${ }^{7}$. En este artículo se emplean las cifras de exportaciones correspondientes a España, Alemania, Francia e Italia, las economías de mayor tamaño de la UEM cuyas cuotas de exportación han mostrado un comportamiento muy dispar en los años recientes. El periodo de análisis se extiende desde el año 2000 hasta el año 2009, en lugar de centrarse en un único año, como sucede en la mayoría de los trabajos realizados hasta ahora. Esta perspectiva temporal nos permitirá indagar en la estrategia que han seguido los exportadores en términos de variedad y precios relativos, ante la competencia creciente de las economías emergentes. Como es habitual, los precios de exportación de cada producto se aproximan por su valor unitario, esto es, el valor de exportación dividido por la cantidad exportada. Hay que destacar que la clasificación empleada ha registrado cambios relevantes en los años 2002 y 2007 con el fin de adaptarse a los cambios en la demanda internacional, que ha supuesto la aparición de algunas nuevas partidas, en tanto que otras se eliminan o renombran, sin que exista una correspondencia biunívoca que permita enlazar los datos de las distintas clasificaciones. Dado que este cambio afectó a todos los países y que en este trabajo los cálculos se presentan en términos relativos, tomando como referencia el mundo, cabe esperar que estos cambios metodológicos no afecten a las conclusiones que se extraen ${ }^{8}$.

\footnotetext{
${ }^{7}$ Una alternativa sería utilizar la base de datos BACI que corrige algunos de los problemas relacionados con errores de medida y de clasificación de productos que presenta la base de datos COMTRADE.

${ }^{8}$ MARTIN. y MÉJEAN (2011) es uno de los pocos trabajos en los que se presta especial atención a la ruptura en la serie que introduce el cambio en la clasificación del Sistema Armonizado. Para ello aplican el procedimiento propuesto por PIERRE y SCHOTT (2011),
} 
Las cifras se han sometido a un proceso de depuración para eliminar valores anómalos o algunos productos que presentan características de oferta y demanda específicas. En concreto, en este trabajo no se tienen en cuenta las cifras relativas al comercio de animales vivos, productos petrolíferos, joyas y obras de arte y otros productos no clasificados (capítulos 01, 27, 98 y 99, respectivamente). Por otra parte, sólo se han tenido en cuenta aquellas categorías para las que la información relativa a la cantidad exportada es un valor positivo distinto de cero y está disponible en kilos (en torno a 4.800 productos, que representan entre el 95 por 100-98 por 100 del total de las exportaciones de bienes en cada país en el periodo 2000-2009). Finalmente, se eliminan algunas partidas para la que la información relativa a los precios de las cuatro economías consideradas presenta una variación muy elevada, que sugiere la presencia de errores en el suministro de información u otro tipo de anomalía ${ }^{9}$. En conjunto, el valor de las exportaciones obtenido tras la aplicación de estos filtros supone un 93 por 100 del total de las exportaciones en los cuatro países considerados. Esta depuración justifica que las cuotas que se presentan en este artículo no coincidan exactamente con las que se obtienen al emplear los datos agregados. Pero las diferencias son muy reducidas en las cuatro economías consideradas.

Hay que mencionar que a la hora de definir la variedad o el grado de diversificación de las exportaciones, en este trabajo se considera que dos posiciones distintas de la clasificación del comercio internacional al máximo nivel de desagregación considerado, o una misma posición con un destino diferente, representan dos productos o categorías de producto distintas con incidencia en el cálculo de los márgenes.

Por otra parte, la calidad no es observable y la aproximación a través de los precios no está exenta de problemas. Este procedimiento tiene su sustento en la teoría microeconómica, que sugiere que la diferenciación vertical o en términos de calidad de los productos puede aumentar la disposición de los consumidores a pagar un precio mayor por un bien determinado. De este modo, las diferencias en los niveles de precios se relacionan con diferencias en la calidad de la producción. Pero hay muchas razones por las que distintos niveles de los IVU pueden no ser representativos de la calidad. Por ejemplo, las barreras arancelarias pueden distorsionar los precios de exportación (a calidades equivalentes, los países que se enfrentan a mayores aranceles deberán reducir sus precios para competir). Los costes de producción y los tipos de cambio también pueden generar distorsiones (por ejemplo, los productos chinos son más baratos porque su coste de producción es menor sin que ello implique que su calidad sea inferior). Tampoco se debe olvidar que incluso empleando los datos a un nivel de desagregación de 6 dígitos, las categorías consideradas en las estadísticas de comercio no permiten identificar, en ocasiones, un

9 Para ello se calcula la desviación típica de los precios de los cuatro países considerados, relativos a los precios del total del mundo, a un nivel de rúbrica de la HS a seis dígitos y de mercado. Se eliminan aquellas partidas en las que la desviación típica es superior a 10. Estas partidas se eliminan para todo lo países considerados. 
único producto ${ }^{10}$. Además, las diferencias en precio pueden deberse también a la existencia de diferenciación horizontal de la producción (diferencias en diseño, por ejemplo). En esta línea, Hallack y Schott (2008) desarrollan un procedimiento para inferir las diferencias en la calidad que se derivan de los IVU y de las balanzas comerciales de los países y encuentran diferencias notables en la evolución de los índices ajustados de calidad y de los IVU (véase también Pula y Santabárbara, 2011).

Como se ha dicho, para calcular el margen extensivo e intensivo se va a seguir la aproximación propuesta por Hummels y Klenow (2005) y Van Hove (2007), que aplican la metodología de Feenstra (1994). Según estos autores, la cuota de exportación de un país determinado $(j)$ en el total mundial puede descomponerse en dos factores: en primer lugar, el nivel de las exportaciones o de la cuota refleja hasta qué punto el país en cuestión vende un mayor o menor valor de cada producto en cada mercado, en relación con el resto del mundo, esto es, el margen intensivo. En segundo lugar, el valor de la cuota será mayor cuanto mayor sea el número de productos y mercados a los que exporta, lo que se denomina el margen extensivo. A su vez, el margen intensivo se puede descomponer en dos elementos ya que el mayor valor de las exportaciones puede deberse a que exportan mayores cantidades físicas de cada bien, o a que el precio de los productos exportados es más elevado. Bajo el supuesto de que los precios de los productos exportados aproximan su calidad, este último factor recibe habitualmente la denominación de margen cualitativo, aunque como se comentó anteriormente, los resultados han de interpretarse con cautela ya que no se puede identificar directamente las variaciones o niveles de los precios relativos con variaciones en la calidad.

En particular, el margen extensivo del país j se define como:

$$
M E_{j m}=\frac{\Sigma_{k \in K_{j m}} P_{l m k} x_{l m k}}{\sum_{k \in K l m} P_{l m k} x_{l m k}}
$$

Donde $m$ es el mercado de destino de las exportaciones y $k$ el producto o categoría de producto exportado a nivel de 6 dígitos de la HS. $K_{j m}$ es el conjunto total de productos que exporta el país $j$ a cada destino $m, K_{l m}$ es el total de productos exportados por el mundo a cada destino $m$ y, finalmente, $P_{l m x} x_{l m k}$ es el valor del producto $k$ exportado por el mundo $l$ al mercado $m$, siendo $P$ el precio y $x$ la cantidad exportada. De acuerdo con esta aproximación el margen extensivo podría interpretarse como el peso que tienen los productos o categorías exportadas por un país determinado a los distintos mercados de destino, en el total de productos o categorías exportadas a nivel

10 Los sesgos que se derivan de esta circunstancia pueden ser elevados. Como mencionan BALDWIN y HARRIGAN (2011). Incluso a un nivel de desagregación de 10 dígitos del Sistema Armonizado hay rúbricas, que incorporan claramente distintos productos (por ejemplo: «jerseys de lana de mujeres y niñas»; «motores de vehículos de entre 1.500 a 3.000 cc» o «lasers, distintos del láser de diodos»). 
mundial por todos los países. Una alternativa a este índice es aproximar la diversificación contando el número de productos y mercados de exportación de cada país, en relación con el total mundial. La principal desventaja de esta alternativa es que cada producto tiene la misma incidencia, con independencia del valor exportado, en tanto que en el índice propuesto por Hummels y Klenow (2005) se tiene en cuenta el valor de cada variedad en el total de las exportaciones de cada país.

Por su parte, el margen intensivo puede expresarse como:

$$
M I_{j m}=\frac{\Sigma_{k \in K_{j m}} P_{j m k} x_{j m k}}{\sum_{k \in K j m} P_{l m k} x_{l m k}}
$$

Esto es, la cuota de las exportaciones del país $j$ en el mercado $m$, pero teniendo en cuenta que en el denominador, en lugar de considerar el total de las exportaciones mundiales al mercado $m$, sólo se consideran aquellas categorías o productos en los que el país $j$ exporta.

Como puede comprobarse, el producto de ambos márgenes es igual a la cuota de exportación del país $j$ en el mercado $m$ :

$$
M E_{j m} M I_{j m}=\frac{\Sigma_{k \in K j m} P_{j m k} x_{j m k}}{\sum_{k \in K l m} P_{l m k} x_{l m k}}
$$

A su vez, el margen intensivo puede descomponerse en dos índices que se corresponden con los precios y con las cantidades relativas, de acuerdo con la expresión $M I_{j m}=P_{j m} Q_{j m}$. La expresión de los precios es:

$$
P_{j m}=\prod_{k \in K_{j m}}\left(\frac{P_{j m k}}{P_{l m k}}\right)^{w_{j m k}}
$$

Para cada producto y mercado se calculan los precios relativos del país $j$, en relación con el total mundial $(l)$ y estos índices se agregan utilizando las ponderaciones que se calculan según la siguiente expresión, que no es más que una media logarítmica de lo que representa ese producto-mercado en el total de las exportaciones del país $j$ (lo que se denomina abajo $S_{j m k}$ ) y lo que representa en el total de las exportaciones mundiales (calculadas sólo para la cesta de los productos que exporta el país $j$ ) $\left(S_{l m k}\right)^{11}$.

$$
S_{j m k}=\frac{P_{j m k} x_{j m k}}{\Sigma_{k \in K j m} P_{j m k} x_{j m k}}
$$

\footnotetext{
${ }^{11}$ Los índices de precios relativos no se calculan para una cesta de productos constante a lo largo del período de tiempo considerado, de modo que su evolución refleja no sólo la exportación de segmentos de calidad superior de un mismo producto, sino también cualquier posible desplazamiento de la exportación hacia productos ó mercados donde el país en cuestión fija unos de precios de exportación superiores, en comparación con el total mundial (FEENSTRA, 1994).
} 


$$
\begin{array}{r}
S_{l m k}=\frac{P_{l m k} x_{l m k}}{\Sigma_{k \in K_{j m}} P_{l m k} x_{l m k}} \\
w_{j m k}=\frac{\frac{S_{j m k}-S_{l m k}}{\ln S_{j m k}-\ln S_{l m k}}}{\Sigma_{k \in K_{j m}} \frac{S_{j m k}-S_{l m k}}{\ln S_{j m k}-\ln S_{l m k}}}
\end{array}
$$

A continuación se presentan los valores de estos índices estimados para España, Alemania, Francia e Italia.

\section{Principales resultados}

En el Cuadro 1 se detalla para el promedio de los años empleados en este trabajo (2000-2009) el número de productos o categorías de productos existentes en la base de datos para cada país, el número de mercados de destino y el número de relaciones comerciales o pares de productos-mercados de destino para los que las exportaciones son distintas de cero. Como se puede apreciar, de los 5.103 productos exportados por el mundo en el promedio 2000-2009, España estuvo presente en 4.847 , por encima de lo observado en Alemania, Francia o Italia. A nivel de mercados, España exportó a 220 de los 245 países posibles, algo por debajo de lo observado en Alemania, Francia e Italia. Estas cifras sugieren, por tanto, una elevada diversificación de los cuatro países por productos y mercados de destino. Cuando se consideran los pares producto-mercado las diferencias son algo mayores ya que España exportó en un promedio de 265.000 pares producto-país y Alemania en 400.000 pares, de los 1.067.000 pares observados en el total mundial. 
CUADRO 1

CARACTERÍSTICAS DE LA BASE DE DATOS

\begin{tabular}{|c|c|c|c|c|c|c|}
\hline & \multicolumn{3}{|c|}{ España } & \multicolumn{3}{|c|}{ Alemania } \\
\hline & Productos & Países & $\begin{array}{c}\text { Relaciones } \\
\text { comerciales }\end{array}$ & Productos & Países & $\begin{array}{c}\text { Relaciones } \\
\text { comerciales }\end{array}$ \\
\hline 2000 & 4.950 & 212 & 217.215 & 4.926 & 218 & 400.164 \\
\hline 2005 & 4.920 & 219 & 273.491 & 4.816 & 230 & 427.775 \\
\hline 2006 & 4.937 & 221 & 282.576 & 4.802 & 232 & 436.026 \\
\hline 2007 & 4.668 & 223 & 282.522 & 4.539 & 234 & 429.290 \\
\hline 2008 & 4.667 & 226 & 287.048 & 4.546 & 234 & 433.455 \\
\hline 2009 & 4.635 & 219 & 287.826 & 4.585 & 234 & 456.273 \\
\hline \multirow[t]{3}{*}{ 2000-2009 (a) } & 4.847 & 220 & 264.986 & 4.774 & 230 & 424.660 \\
\hline & \multicolumn{3}{|c|}{ Francia } & \multicolumn{3}{|c|}{ Italia } \\
\hline & Productos & Países & $\begin{array}{c}\text { Relaciones } \\
\text { comerciales }\end{array}$ & Productos & Países & $\begin{array}{c}\text { Relaciones } \\
\text { comerciales }\end{array}$ \\
\hline 2000 & 4.906 & 217 & 341.675 & 4.960 & 219 & 349.184 \\
\hline 2005 & 4.834 & 226 & 332.850 & 4.892 & 227 & 367.764 \\
\hline 2006 & 4.823 & 227 & 337.815 & 4.905 & 229 & 375.829 \\
\hline 2007 & 4.559 & 230 & 338.025 & 4.617 & 225 & 365.519 \\
\hline 2008 & 4.544 & 231 & 336.523 & 4.629 & 224 & 366.649 \\
\hline 2009 & 4.532 & 229 & 326.544 & 4.610 & 224 & 359.429 \\
\hline \multirow[t]{3}{*}{$2000-2009$ (a) } & 4.758 & 226 & 335.213 & 4.823 & 224 & 361.718 \\
\hline & \multicolumn{3}{|c|}{ Total mundial } & & & \\
\hline & Productos & Países & $\begin{array}{c}\text { Relaciones } \\
\text { comerciales }\end{array}$ & & & \\
\hline 2000 & 5.132 & 248 & 1.067 .328 & & & \\
\hline 2005 & 5.106 & 241 & 1.031 .366 & & & \\
\hline 2006 & 5.098 & 242 & 1.044 .541 & & & \\
\hline 2007 & 5.089 & 242 & 1.067 .719 & & & \\
\hline 2008 & 5.069 & 242 & 1.075 .776 & & & \\
\hline 2009 & 5.036 & 242 & 1.057 .726 & & & \\
\hline 2000-2009 (a) & 5.103 & 245 & 1.067 .395 & & & \\
\hline
\end{tabular}

NOTA (a) Promedio período 2000-2009.

FUENTE: Elaboración propia a partir de United Nations COMTRADE database.

Por lo que se refiere a la descomposición de las cuotas de exportación en términos del margen extensivo e intensivo, en el Cuadro 2 y Gráfico 2 pueden apreciarse que, a diferencia de lo que obtenían Cuadras y Puig (2008), en los años recientes, el menor nivel de la cuota de exportación de España se explica sobre todo por la reducida contribución del margen intensivo, esto es, la cuota de exportación, pero calculada no para el total mundial sino solo para aquellos productos y mercados en los 
que España exporta que, como se aprecia en el cuadro, se situaba próxima al 2,5 por 100 en 2009. El margen extensivo es algo inferior al registrado en Alemania, Francia o Italia, pero ha aumentado notablemente desde el año 2000, acercándose al de Francia. Este resultado sugiere que las empresas exportadoras españolas han ido aumentando su presencia en un número cada vez más elevado de mercados y con mayor diversidad de productos. En cambio, la intensidad exportadora es, en general, reducida y apenas ha variado, al igual que en el resto de países, a lo largo de la década. Aunque las divergencias en el tamaño de las distintas economías puede contribuir a explicar parte de las diferencias, cabe recordar que Cuadras y Puig (2008) encuentran evidencia de que tanto el grado de diversificación, como la intensidad exportadora de España, es inferior a la que cabría esperar considerando el nivel de desarrollo de la economía española.

Esta evidencia es coherente con los resultados que se desprenden de algunos estudios realizados con datos a nivel de empresas que muestran que las empresas españolas han accedido con dinamismo a los mercados exteriores, pero no logran consolidar su posición en dichos mercados. Los estudios realizados con datos micro revelan que, a pesar de los elevados costes de entrada, la mayor parte de las empresas españolas cesa su actividad con el exterior al año siguiente de iniciarla, y tan solo

CUADRO 2

\begin{tabular}{|c|c|c|c|c|c|c|}
\hline & & España & & & Alemania & \\
\hline & $\begin{array}{l}\text { Margen } \\
\text { exten. }\end{array}$ & $\begin{array}{c}\text { Margen } \\
\text { inten. }\end{array}$ & Cuota & $\begin{array}{c}\text { Margen } \\
\text { exten. }\end{array}$ & $\begin{array}{c}\text { Margen } \\
\text { inten. }\end{array}$ & Cuota \\
\hline 2000 & 79,93 & 2,34 & 1,87 & 89,42 & 11,02 & 9,86 \\
\hline 2005 & 83,33 & 2,39 & 1,99 & 89,89 & 12,22 & 10,99 \\
\hline 2006 & 81,94 & 2,17 & 1,78 & 89,78 & 12,13 & 10,89 \\
\hline 2007 & 81,27 & 2,17 & 1,76 & 89,37 & 11,69 & 10,45 \\
\hline 2008 & 82,82 & 2,40 & 1,99 & 89,27 & 12,44 & 11,11 \\
\hline \multirow[t]{3}{*}{2009} & 83,27 & 2,43 & 2,03 & 91,47 & 11,99 & 10,97 \\
\hline & \multicolumn{3}{|c|}{ Francia } & \multicolumn{3}{|c|}{ Italia } \\
\hline & $\begin{array}{c}\text { Margen } \\
\text { exten. }\end{array}$ & $\begin{array}{c}\text { Margen } \\
\text { inten. }\end{array}$ & Cuota & $\begin{array}{c}\text { Margen } \\
\text { exten. }\end{array}$ & $\begin{array}{c}\text { Margen } \\
\text { inten. }\end{array}$ & Cuota \\
\hline 2000 & 88,92 & 5,98 & 5,32 & 87,84 & 4,85 & 4,26 \\
\hline 2005 & 87,84 & 5,34 & 4,69 & 87,56 & 4,45 & 3,90 \\
\hline 2006 & 85,05 & 4,97 & 4,23 & 87,33 & 4,37 & 3,82 \\
\hline 2007 & 81,52 & 4,52 & 3,68 & 86,07 & 4,50 & 3,87 \\
\hline 2008 & 84,46 & 4,86 & 4,10 & 85,80 & 4,48 & 3,85 \\
\hline 2009 & 83,96 & 4,90 & 4,11 & 86,30 & 4,29 & 3,70 \\
\hline
\end{tabular}

FUENTE: Elaboración propia a partir de United Nations COMTRADE database. 


\section{GRÁFICO 2}

\section{COMPONENTES DE LA CUOTA DE EXPORTACIÓN DE BIENES (PERÍODO 2000 Y 2007-2009)}
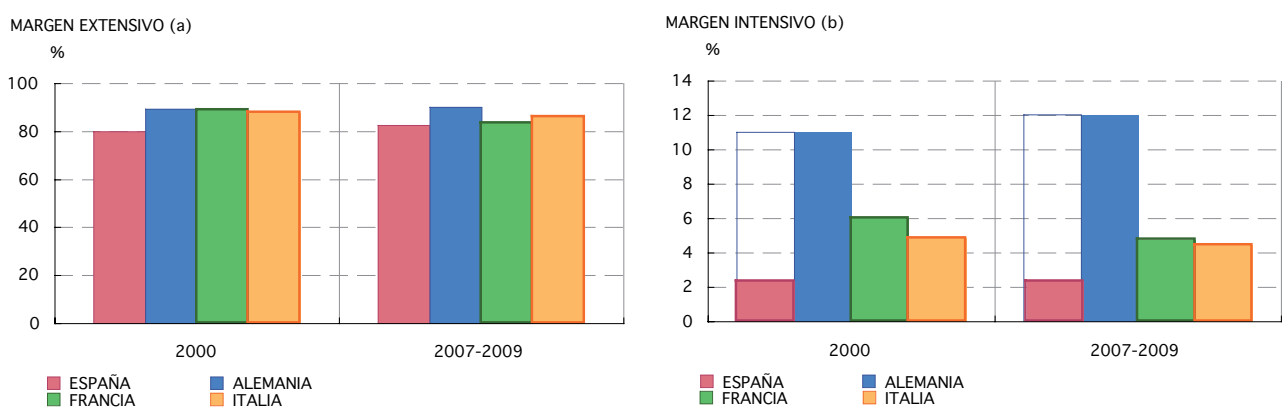

NOTAS: (a) Componente de la cuota de exportación explicada por el número de productos (o categorías) vendidos a los distintos mercado. (b) Componente de la cuota de exportación explicada por la intensidad exportadora o valor vendido de cada producto en cada mercado.

FUENTE: Elaboración propia a partir de United Nations COMTRADE database.

alrededor del 7 por 100 de las empresas españolas exportadoras de bienes que iniciaron su actividad internacional en 2001 continuaba exportando en 2007 (véase Martín y Rodríguez, 2009, y Martín et al., 2009).

Cuando se analiza la evolución del margen intensivo y extensivo distinguiendo entre las principales áreas geográficas se advierte que, en general, en los cuatro países considerados, la diversificación de las exportaciones es menor en los mercados de fuera de la UEM, y, en particular, en las economías menos desarrolladas, lo que es consistente con la existencia de costes de entrada superiores en esos países, que hacen que solo las empresas más productivas puedan acceder. En el caso de España, el margen extensivo revela que la diversificación de las exportaciones es inferior a la de Alemania, Francia e Italia en todas las áreas consideradas, y muy especialmente en los países asiáticos y otras economías menos desarrolladas (véase Gráfico 3 y Cuadro A1). Pero lo que destaca en el caso de España es el aumento de la diversificación (margen extensivo) que se produce precisamente en esos mercados asiáticos, que se encuentran cultural y geográficamente más alejados de la economía española ${ }^{12}$. Por el contrario, la intensidad exportadora se ha mantenido prácticamente estable a lo largo del período (véanse Cuadro 2 y Gráfico 4). Este resultado es relativamente favorable, si se tiene en cuenta lo sucedido en Francia o Italia en esos mismos años, que registraron una paulatina contracción de su margen intensivo en esos mercados. Aun así, el margen intensivo de la economía española sigue siendo muy reducido.

En síntesis, los resultados indican que los exportadores españoles han hecho un esfuerzo para diversificar sus exportaciones vendiendo una mayor variedad de pro-

12 En MARTIN (2011), empleando una ecuación de gravedad, se encuentra que, a pesar de la diversificación reciente, las todavía moderadas exportaciones de España a áreas emergentes no pueden explicarse por las diferencias culturales y la distancia geográfica existente. 
GRÁFICO 3

MARGEN EXTENSIVO. DESGLOSE POR ÁREAS GEOGRÁFICAS (PERÍODO 2000 Y 2007-2009)
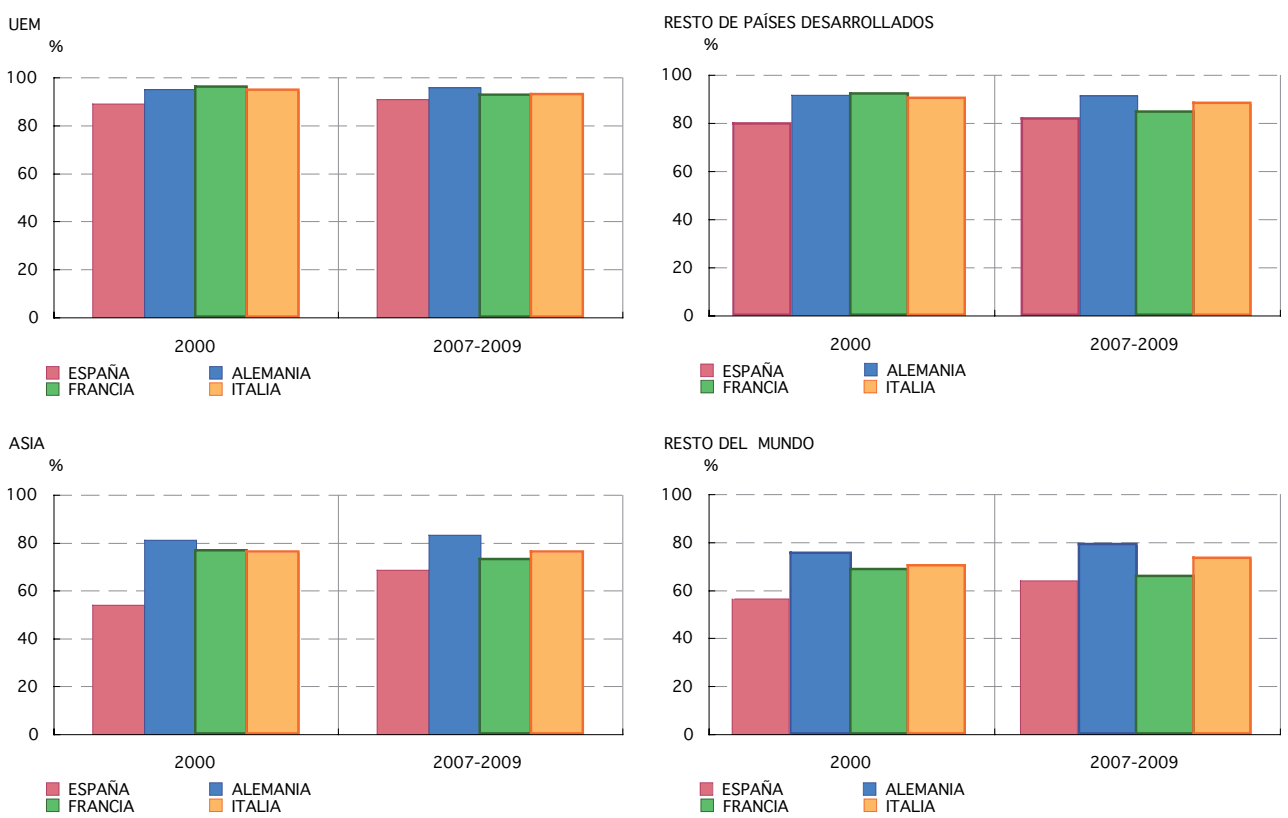

FUENTE: Elaboración propia a partir de United Nations COMTRADE database.

ductos a más mercados, pero parece tener problemas para consolidar su posición en el exterior y, por tanto, para expandir el valor de sus ventas de una manera significativa. Alemania, en cambio, registra un aumento generalizado de su intensidad exportadora en todas las áreas (con la excepción del resto del mundo), y ello a pesar de los elevados niveles de partida de este indicador (véase Gráfico 4). En Francia, en cambio, el retroceso de su cuota de exportación revela un descenso generalizado de su intensidad exportadora, pero también un paulatina caída de la diversificación por productos y mercados, especialmente entre los países asiáticos. En Italia los resultados son más dispares: la caída de la cuota en la UEM se debe principalmente al retroceso de la intensidad exportadora, mientras que en los mercados asiáticos y en las economías menos desarrolladas la mayor diversificación por productosmercados ha compensado en parte el retroceso de la intensidad exportadora.

La descomposición del margen intensivo en sus dos componentes, precios y cantidades, permite indagar en algunas de las razones que podrían estar detrás de la baja intensidad exportadora de la economía española. Nuestro interés se centra especialmente en el componente de precios relativos que, como se comentó anteriormente, resume la evolución de los precios de exportación de España (Alemania, Francia e Italia), en comparación con los del resto del mundo, calculados a un nivel de desagregación de 6 dígitos de la HS y agregados posteriormente mediante una media logarítmica. 


\section{GRÁFICO 4}

\section{MARGEN INTENSIVO. DESGLOSE POR ÁREAS GEOGRÁFICAS (PERÍODO 2000 Y 2007-2009)}
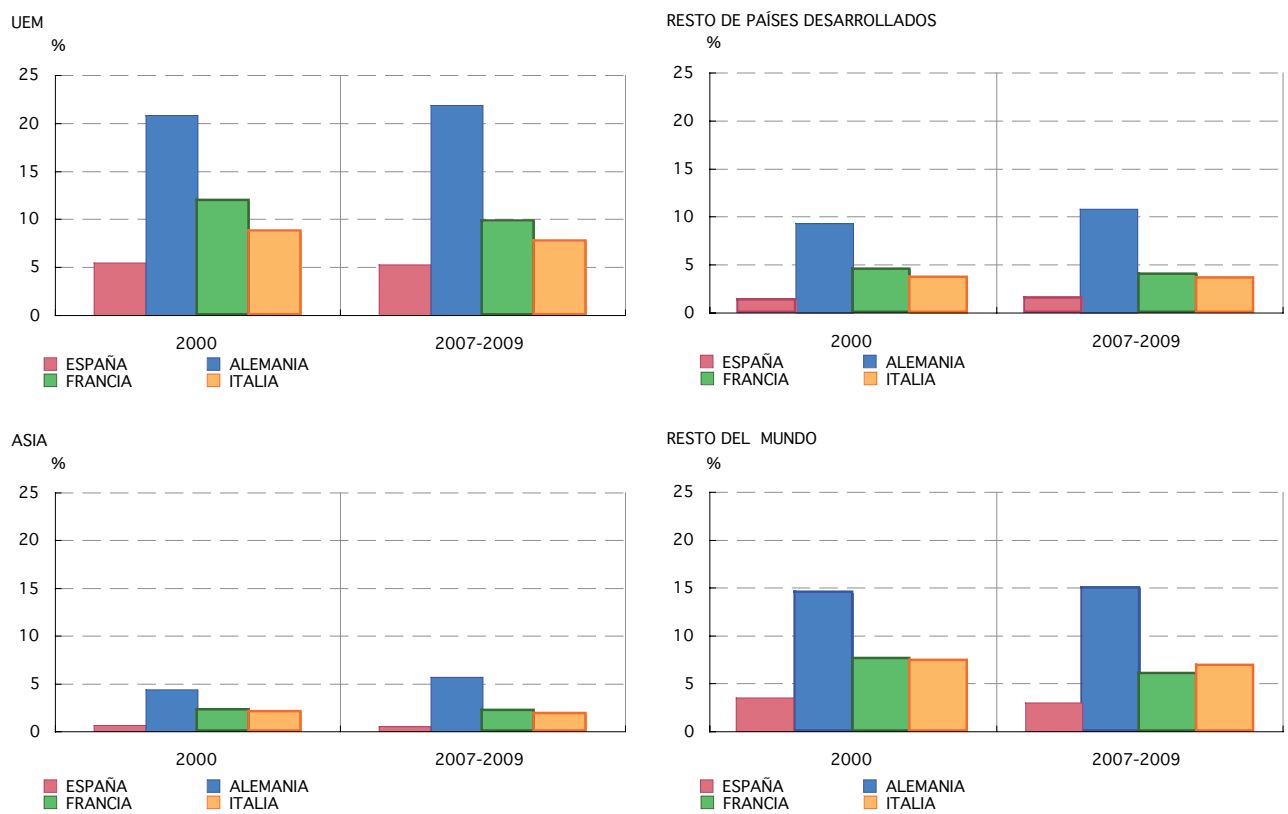

FUENTE: Elaboración propia a partir de United Nations COMTRADE database.

Como se puede apreciar en el Cuadro 3, los niveles de los IVU de exportación de España no difieren de manera significativa de los del resto del mundo (con la excepción de lo observado en el año 2006). En cambio, Italia y, en mayor medida, Francia y Alemania presentan unos niveles de precios de exportación superiores a los del promedio mundial. Aún teniendo en mente todas las cautelas comentadas anteriormente respecto a asociar diferencias de los niveles de precios con la especialización en distintos segmentos de calidad, el hecho de que las diferencias sean tan persistentes, sobre todo, en el caso de Alemania, induce a pensar que también la calidad puede jugar un papel relevante a la hora de explicar estas divergencias en los niveles de precios. Destaca sobre todo el caso de Alemania que ha mantenido durante todo el período analizado precios de exportación notablemente superiores a los del promedio mundial, sin que ello haya provocado un desplazamiento de su cuota de participación en los mercados mundial. Muy al contrario, como se vio anteriormente, de las cuatro economías analizadas, Alemania es la única que ha incrementado su cuota de manera generalizada.

Asumiendo, por tanto, que las diferencias en precios son indicativas, entre otras cosas, de la aplicación de estrategias de diferenciación de la producción en términos de calidad, los resultados sugerirían que en comparación con las grandes economías de la UEM, España podría estar posicionada en la exportación de segmentos de 
CUADRO 3

COMPONENTES DEL MARGEN INTENSIVO

\begin{tabular}{|c|c|c|c|c|c|c|}
\hline & \multicolumn{3}{|c|}{ España } & \multicolumn{3}{|c|}{ Alemania } \\
\hline & $\begin{array}{c}\text { Margen } \\
\text { inten. }\end{array}$ & Precio & Cantidad & $\begin{array}{c}\text { Margen } \\
\text { inten. }\end{array}$ & Precio & Cantidad \\
\hline 2000 & 2,34 & 1,02 & 2,29 & 11,02 & 1,29 & 8,56 \\
\hline 2005 & 2,39 & 1,07 & 2,24 & 12,22 & 1,42 & 8,62 \\
\hline 2006 & 2,17 & 1,20 & 1,81 & 12,13 & 1,36 & 8,89 \\
\hline 2007 & 2,17 & 1,05 & 2,07 & 11,69 & 1,29 & 9,07 \\
\hline 2008 & 2,40 & 1,01 & 2,38 & 12,44 & 1,32 & 9,44 \\
\hline \multirow[t]{3}{*}{2009} & 2,43 & 1,01 & 2,42 & 11,99 & 1,28 & 9,36 \\
\hline & \multicolumn{3}{|c|}{ Francia } & \multicolumn{3}{|c|}{ Italia } \\
\hline & $\begin{array}{c}\text { Margen } \\
\text { inten. }\end{array}$ & Precio & Cantidad & $\begin{array}{c}\text { Margen } \\
\text { inten. }\end{array}$ & Precio & Cantidad \\
\hline 2000 & 5,98 & 1,28 & 4,68 & 4,85 & 1,13 & 4,30 \\
\hline 2005 & 5,34 & 1,32 & 4,05 & 4,45 & 1,23 & 3,62 \\
\hline 2006 & 4,97 & 1,22 & 4,07 & 4,37 & 1,18 & 3,69 \\
\hline 2007 & 4,52 & 1,24 & 3,65 & 4,50 & 1,17 & 3,86 \\
\hline 2008 & 4,86 & 1,23 & 3,96 & 4,48 & 1,19 & 3,77 \\
\hline 2009 & 4,90 & 1,26 & 3,89 & 4,29 & 1,16 & 3,69 \\
\hline
\end{tabular}

FUENTE: Elaboración propia a partir de United Nations COMTRADE database.

calidad inferior. Esta conclusión se repite tanto en las exportaciones destinadas a la UEM, como en las dirigidas al resto del mundo.

Por otra parte, los precios relativos de exportación de Alemania, Francia e Italia son más elevados en los mercados situados fuera de la UEM, lo que podría indicar que en esos países hay mayores diferencias en las características de los productos exportados por estas tres economías y los exportados por el resto del mundo (véase cuadro A2 del anejo). Por el contrario, en España solo se observan precios más elevados en las economías desarrolladas no euro. De nuevo destaca la caída generalizada de los precios relativos de exportación en los mercados asiáticos en los tres últimos años que, más que variaciones en la calidad de los productos exportados, podría estar reflejando un descenso de los márgenes de los exportadores alemanes, franceses e italianos, ante la moderación de la demanda global y los movimientos del tipo de cambio ${ }^{13}$.

13 Véase DEUTSCHE BUNDESBANK MONTHLY REPORT July 2011, para una descripción de los diferentes factores que podrían explicar la diferente evolución de las exportaciones en las cuatro grandes economías de la UEM. 
Otra manera alternativa de medir la posición relativa de las exportaciones españolas en segmentos de calidad es la empleada por Fontagné et al. (2008), que consiste en distribuir el valor de las exportaciones de cada país en 3 segmentos, alta, media y baja, de acuerdo con el valor de sus precios de exportación en relación con los del resto de las economías consideradas y del resto del mundo. Esto es, para cada par de producto-mercado se calcula la distribución de los precios de exportación; si el precio de un país en concreto se sitúa por encima del percentil 67, el valor de las exportaciones de ese producto-mercado se asigna al segmento de calidad superior; en cambio, si es inferior al percentil 33, el valor de las exportaciones se asigna al segmento de calidad inferior; y si el precio se encuentra entre ambos percentiles se considera que las exportaciones son de calidad intermedia. En el Cuadro 4 se presenta la distribución de las exportaciones de las cuatro economías consideradas clasificadas por segmentos de calidad siguiendo este procedimiento.

\section{CUADRO 4}

DISTRIBUCIÓN DE LA CUOTA DE MERCADO SEGÚN SEGMENTOS DE PRECIO/CALIDAD

\begin{tabular}{lcccc}
\hline & Calidad media & Calidad alta & Calidad baja & Total cuota \\
\hline Alemania & & & & \\
\hline 2000 & 56,0 & 32,6 & 11,4 & 100,0 \\
\hline 2005 & 58,6 & 32,8 & 8,6 & 100,0 \\
\hline 2008 & 57,3 & 33,8 & 8,9 & 100,0 \\
\hline España & & & 29,3 & 100,0 \\
\hline 2000 & 55,1 & 15,6 & 34,9 & 100,0 \\
\hline 2005 & 52,8 & 12,4 & 28,7 & 100,0 \\
\hline 2008 & 57,9 & 13,4 & 16,0 & 100,0 \\
\hline Francia & & & 15,5 & 100,0 \\
\hline 2000 & 59,0 & 25,0 & 16,6 & 100,0 \\
\hline 2005 & 56,3 & 28,2 & & \\
\hline 2008 & 60,7 & 22,8 & 20,3 & 100,0 \\
\hline Italia & & & 21,0 & 100,0 \\
\hline 2000 & 60,2 & 19,5 & 19,6 & \\
\hline 2005 & 60,1 & 18,9 & & \\
\hline 2008 & 59,7 & 20,7 & & \\
\hline
\end{tabular}

FUENTE: Elaboración propia a partir de United Nations COMTRADE database. 
Como se puede apreciar, Alemania es el país con mayor proporción de sus exportaciones situadas en los segmentos de calidad superior y, además, presenta una menor participación de los segmentos de menor calidad. En cambio, en el caso de España casi un tercio de las exportaciones se situaría en los segmentos de menor calidad y no parece que esta circunstancia se haya modificado notablemente a lo largo de la última década. Parece por tanto que la economía española no ha cerrado la brecha de calidad respecto a Alemania, Francia e Italia, aunque en comparación con el resto del mundo la calidad media de sus productos se sitúa en torno al promedio. No obstante, cabe mencionar que Fontagné et al. (2008) emplean los precios de un conjunto mucho más amplio de exportadores que el considerado en este trabajo para distribuir las exportaciones por segmentos de calidad y aunque las conclusiones que aquí se obtienen no difieren de las de estos autores, hay que tomar estos resultados con las debidas cautelas. La futura ampliación de la base de datos empleada en este trabajo con un número mayor de países, permitirá profundizar en el conocimiento de la posición relativa de la economía española en lo que respecta a la especialización en segmentos de calidad.

\section{Determinantes de las diferencias en los precios de exportación de España desde la perspectiva de la demanda}

Por lo que respecta a los determinantes de la heterogeneidad observada en los márgenes intensivo y extensivo y en los niveles de precios a nivel de producto y mercado, la literatura empírica ha puesto un mayor énfasis en el análisis de los factores de oferta, relacionando el nivel de estos indicadores con el tamaño del país exportador, su grado de desarrollo relativo, la capacidad tecnológica y la dotación de capital humano cualificado. El hecho de que nuestra base solo contenga información relativa a las cuatro economías de la UEM y al total mundial, limita mucho el análisis de los determinantes que se puede realizar desde esta perspectiva.

Pero como se dijo anteriormente, en el caso concreto de los precios, la evidencia empírica disponible revela una elevada heterogeneidad en los precios de venta de un mismo producto a los diferentes países y que éstas diferencias dependen en buena medida de las características de los mercados de destino y, en particular, de su tamaño, de su nivel de renta per cápita, que recoge la preferencia de los consumidores por la variedad y la calidad y de la distancia, que trata de aproximar los costes de exportación ${ }^{14}$. Para contrastar si en el caso de la economía española se mantienen estas relaciones empíricas se ha realizado una regresión entre los precios de exportación (valores unitarios) de un mismo producto dirigido a los distintos países, y la

\footnotetext{
14 Este resultado a nivel agregado, es ratificado por los datos a nivel de empresa, que sugieren que los exportadores seleccionan los productos que venden en cada mercado, exportando, en media, los productos de mayor calidad y mayor precio a los mercados más lejanos y con una mayor renta per cápita.
} 
distancia, el tamaño de los mercados y su nivel de renta per cápita, de acuerdo con la siguiente ecuación:

$$
\ln I V U i k=\mu i+\infty \ln D I S T i+\beta \ln Y i+\gamma \ln \left(\frac{Y}{P}\right) i+\varepsilon i k
$$

La variable dependiente son los valores unitarios de las exportaciones españolas, desagregados por los $k$ productos disponibles al nivel de desagregación de seis dígitos según la HS, y por mercados (i), en el año 2008. El tamaño del país importador se aproxima por el PIB anual nominal valorado en dólares y expresado en paridad de poder de compra; el nivel de renta es el PIB per-cápita medido también en dólares y en paridad de poder de compra (PPP); finalmente, la distancia son los kilómetros existentes entre las capitales de cada país con la de España. La ecuación se estima por mínimos cuadrados ordinarios, con efectos fijos por producto $(\mu i)$, para controlar, por ejemplo, por los distintos niveles de precios existentes entre las diferentes categorías o productos. Las variables de PIB y PIB per-cápita proceden del Banco Mundial y de Naciones Unidas, mientras que para la distancia se han empleado los datos procedentes del Centre d'Études Prospectives et d'Informations Internationales (CEPII).

La relación esperada entre la renta per cápita del mercado de destino y los precios de exportación es positiva ya que los países más ricos demandarán las variedades de la producción de calidad superior y estarán dispuestos a pagar un mayor precio por ellas. En cuanto a la distancia, los modelos de heterogeneidad empresarial con diferenciación en términos de calidad (como el de Baldwin y Harrigan (2011)) sugieren que, dado que en general los costes de exportación aumentan con la distancia, solo las empresas más productivas y con mayores precios (calidad) podrán asumir los mayores costes que conlleva la exportación a mercados lejanos, pero también en los modelos con productos homogéneos tiene cabida las estrategias de diferenciación de precios por mercados de destino (pricing to market). Finalmente, la relación entre el tamaño del mercado y el precio de exportación no es evidente: por un lado, en mercados grandes el nivel de competencia es más elevado, lo que puede motivar que las empresas se vean obligadas a contener en mayor medida sus precios y que las empresas menos productivas se vean forzadas a abandonarlos (Kneller y Yu, 2008, y Bastos y Silva, 2010). Por otro lado, los mercados grandes suelen presentar una mayor variedad de la demanda, lo que hace que las empresas menos productivas pueden encontrar beneficioso exportar variedades de calidad inferior (Baldwin y Harrigan, 2011).

En los diferentes paneles del Gráfico 5 se representan los precios de exportación frente cada una de los tres variables incluidas en la ecuación. Como se puede apreciar, los valores unitarios de exportación de España también presentan una heterogeneidad elevada a nivel de producto. Además, los gráficos revelan una correlación positiva entre los precios de exportación de los productos o categorías dirigidos a los distintos mercados, y el tamaño, la renta per-cápita y la distancia del país de destino de la exportación. 

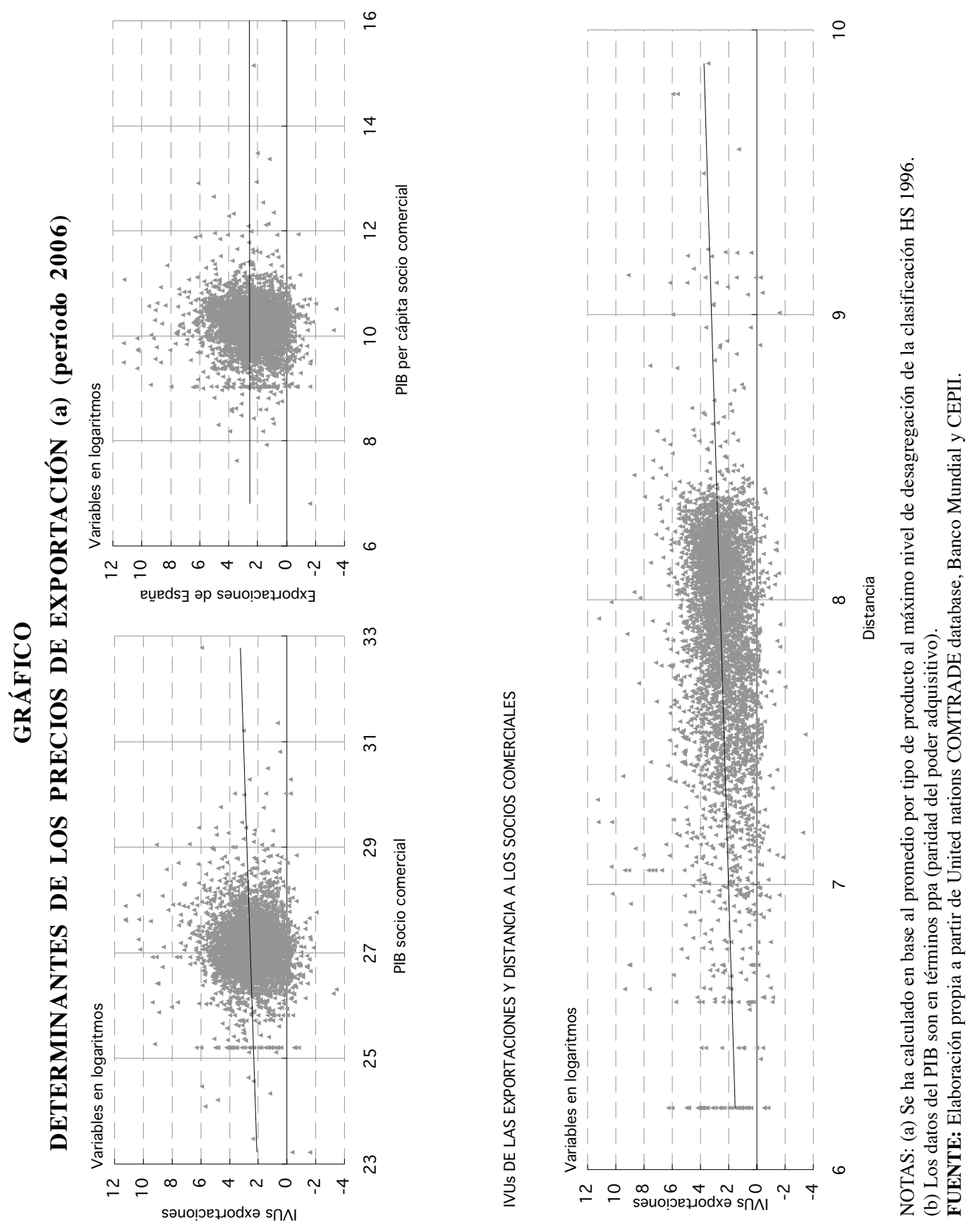
Finalmente, en el cuadro 5 se presentan los resultados de estimar la ecuación [6]. Como se puede apreciar los resultados son consistentes con las relaciones teóricas comentadas anteriormente. Los IVUs de exportación de España disponibles para cada producto, aumentan con la distancia existente hasta el mercado de destino, lo que en los modelos de heterogeneidad empresarial podría justificarse por el hecho de que sólo las empresas más productivas, que venden a precios superiores, encuentran rentable afrontar los costes que entraña la penetración en esos mercados. Las estimaciones indican que si la distancia al país importador se duplica, el valor unitario de la exportación se incrementaría en torno a un 11 por 100. También se aprecia una relación positiva entre el grado de desarrollo del país importador y el precio de las exportaciones españolas, en consonancia con la evidencia disponible para otros países que revela que, en general, los países de renta más alta, tienden a demandar productos de mayor calidad. No obstante, las estimaciones revelan que los precios de exportación de España para un mismo producto son menores cuanto mayor es el tamaño del mercado de destino de un producto. Este resultado es consistente con el modelo de Baldwin y Harrigan (2011) que establece que un mayor tamaño del mercado de exportación supone que habrá un mayor número de empresas de productividad (calidad) inferior que encontrarán rentable vender en ese mercado, disminuyendo por tanto los precios de exportación medios. No obstante el ajuste de la ecuación es muy reducido, por lo que en un futuro se considerará la inclusión de otras variables que pueden resultar relevantes, como los tipos de cambio bilaterales, la pertenencia a la UE o a la UEM y la existencia de un lenguaje común, como en las ecuaciones de gravedad (Baldwin y Harrigan, 2011).

\section{CUADRO 5}

RESULTADOS DE LA REGRESIÓN. FACTORES EXPLICATIVOS DE LOS IVU DE EXPORTACIÓN (A) (PERIODO 2008)

\begin{tabular}{|l|r|r|}
\hline & Coeficiente & t-estadístico \\
\hline PIB ppa nominal del socio comercial & $-0,047$ & $-27,40$ \\
PIB ppa per cápita nominal del socio comercial & 0,056 & 27,59 \\
Distancia & 0,108 & 34,17 \\
\hline R cuadrado & \multicolumn{2}{|c|}{0,013} \\
Test F & 62,960 \\
Número de observaciones & \multicolumn{2}{|c|}{130.450} \\
\hline
\end{tabular}

NOTA: (a) Regresión realizada empleando MCO con efectos fijos por productos.Todas las variables están en logaritmos. Errores estándar agrupados por producto.

FUENTE: Elaboración propia a partir de United Nations COMTRADE database. 


\section{Conclusiones}

En este artículo se trata de indagar en los factores que subyacen a la evolución de las cuotas de exportación de bienes de España en los años recientes a partir de la la información de comercio exterior a un nivel muy elevado de desagregación. Siguiendo la metodología desarrollada por Hummels y Klenow (2005), se trata de analizar el papel que ha jugado la diversificación por productos y mercados en los resultados comerciales de España (margen extensivo), la evolución de la intensidad exportadora (margen intensivo) y la importancia que tienen las estrategias de diferenciación en segmentos de calidad de las exportaciones (margen cualitativo). Las principales conclusiones que se derivan de este análisis son:

La evolución comparativamente favorable de la cuota de exportación de España en los mercados mundiales se explica principalmente por el aumento del margen extensivo, esto es, por la mayor diversificación por productos y mercados que se aprecia al máximo nivel de desagregación posible. Este incremento se produce especialmente en los mercados asiáticos y en los países menos desarrollados, donde España tenía una menor presencia a principios de los 2000.

El margen intensivo no ha disminuido, en contraste con lo que se observa en otras economías de nuestro entorno, como Francia o Italia, pero se mantiene en niveles comparativamente reducido.

$\mathrm{Al}$ analizar los precios relativos de exportación se aprecia que, en promedio, España mantiene unos niveles de precios similares a los del total mundial. Pero las economías de nuestro entorno parece que se han posicionado en la exportación de productos de mayor calidad que los españoles. Cuando se analizan los precios de un mismo producto destinado al mismo mercado, la economía española presenta una mayor proporción de exportaciones situadas en los segmento de menor precio, en comparación con Alemania, Francia e Italia.

Los valores unitarios de exportación de España varían de manera significativa según el mercado de destino de la exportación. En consonancia con lo observado en otros países de nuestro entorno, en general, los precios de venta de un mismo producto son más elevados cuanto mayor es la distancia al mercado de destino y su renta per-cápita. En cambio el tamaño del país parece que incide negativamente sobre los precios de exportación.

En resumen, los resultados indican que los exportadores españoles han hecho un esfuerzo para abrir nuevos mercados con nuevos productos, llegando incluso a los países cultural y geográficamente más alejados. Pero en relación con las economías de nuestro entorno, la especialización en segmentos de calidad superior es más reducida. 


\section{Referencias bibliográficas}

[1] ANTRÀS, P.; SEGURA, R. y RODRÍGUEZ, D. (2010): Firms in international trade (with an application to Spain), ponencia presentada en el XXXV Simposio de la Asociación Española de Economía.

[2] BALDWIN, R. y HARRIGAN, J. (2011): «Zero, quality and Space: Trade theory and trade evidence», American Economic Journal: Microeconomics, 3(2), pp. 60-88.

[3] BALDWIN, R. y ITO, T. (2008): «Quality competition versus price competition goods: and empirical classification», NBER, Working Paper n. ${ }^{\circ} 14305$.

[4] BASTOS, P. y SILVA, J. (2010): «The quality of a firm's exports: Where you export to matters», Journal of International Economics, 82, pp. 99-111.

[5] CUADRAS, X. y PUIG, J. (2008): «La variedad y la calidad de las exportaciones españolas», Cuadernos Económicos ICE, n. ${ }^{\circ}$ 76, pp. 157-166.

[6] DEUTSCHE BUNDESBANK (2011): «Developments in the exports of the four largest euro-area member states since the launch of monetary unión», Monthly Report, julio.

[7] FEENSTRA, R.C. (1994): «New product varieties and the measurement of international prices», American Economic Review, vol. 84, n. ${ }^{\circ}$ 1, pp. 157-177.

[8] FONTAGNÉ, L.; GAULIER, G. y ZIGNAGO, S. (2008): «Specialization across varieties and North-South competition», Economic Policy, enero 2008, pp. 53-91.

[9] GARCÍA, C. y TELLO, P. (2011): «La evolución de las cuotas de exportación de los productos españoles en la última década: el papel de la especialización comercial y de la competitividad», Boletín Económico, mayo, Banco de España.

[10] GROSSMAN, G. y HELPMAN, E. (1991): Innovation and growth in the global economy. MIT Press, Cambridge, MA .

[11] HALLAK, J.C. (2006): «Product Quality and the Direction of Trade», Journal of International Economics, 68(1), pp. 238-265.

[12] HALLAK, J.C. y SCHOTT, P. (2008): «Estimating cross-country differences in product quality», National Bureau of Economic Research, Working Paper 13807.

[13] HUMMELS, D. y KLENOW, P. (2005): «The Variety and Quality of a Nations Exports», American Economic Review, 95(3), pp. 704-723.

[14] KHANDELWAL, A. (2010): «The Long and Short (of) Quality Ladders», Review of Economic Studies, 77, pp. 1450-1476.

[15] KNELLER, R. y YU, Z. (2008): «Quality selection, Chinese exports and theories of heterogeneous firm trade», GEP Research Paper 2008/44, University of Nottingham .

[16] KRUGMAN, P. (1979):«A Model of Innovation, Technology Transfer, and the World Distribution of Income», Journal of Political Economy, 87(2), pp. 253-266.

[17] KRUGMAN, P. (1980): «Scale economies, product differentiation and the pattern of trade», The American Economic Review, 70, pp. 1965-1725.

[18] MARTÍN, C. y RODRÍGUEZ, A. (2009): «Una aproximación a las características de las empresas exportadoras españolas», Boletín Económico, mayo, Banco de España.

[19] MARTÍN, C.; RODRÍGUEZ, A. y TELLO, P. (2009): «Determinantes principales de la decisión de exportar de las empresas españolas», Boletín Económico, diciembre, Banco de España.

[20] MARTÍN, C. (2011): «Un análisis del destino geográfico de las exportaciones españolas de bienes a través de una ecuación de gravedad», Boletín Económico, julio-agosto, Banco de España. 
[21] MARTIN, J. y MÉJEAN, I. (2011): «Low-Wage Countries' competition, reallocation across firms and the quality content of exports», EFIGE working paper 37.

[22] MELITZ, M.J. (2003): «The impact of trade on intra-industry reallocations and aggregate industry productivity», Econometrica, 71(6), pp. 1695-1725.

[23] NAVARETTI, G.; BUGAMELLI, M.; SCHIVARDI, F.; ALTOMONTE, C.; HORGOS, D. y MAGGIONI, D. (2011): «The global operations of european firms. The second Efige policy report», Bruegel Blueprint Series, vol XII.

[24] PIERCE, J.R. y SCHOTT, P. (2011): «Concording U.S Harmonized System Categories Over Time», Journal of Official Statistics (forthcoming).

[25] PULA, G. y SANTABÁRBARA, D. (2011): «Is China climbing up the quality ladder? Estimating cross country differences in product quality using Eutostat's COMEXT Database?, ECB Working paper series 1310.

[26] RODRÍGUEZ, D. (2008): «Heterogeneidad y competitividad exterior de las empresas industriales», Papeles de Economía Española, 116, pp. 140-151.

[27] SCHOTT, P. (2004): «Across-Product versus within Product Specialization in International Trade», Quarterly Journal of Economics, 119(2), pp. 647-678.

[28] SUTTON, J. (1986): «Vertical Product Differentiation: some basic themes», The American Economic Review, 76(2), pp. 393-398.

[29] UNITED NATIONS (2008): UN Commodity Trade Statistics Database (UN Comtrade), accessed in June, 2008 at http://comtrade.un.org/

[30] VAN HOVE, J. (2007): «Pattern and determinants of variety and quality of intra-European trade» (ETSG Athens ). Mimeo.

[31] VERHOOGEN (2008): «Trade, Quality Upgrading and Wage Inequality in the Mexican Manufacturing Sector», Quarterly Journal of Economics, 123(2), pp. 489-530. 


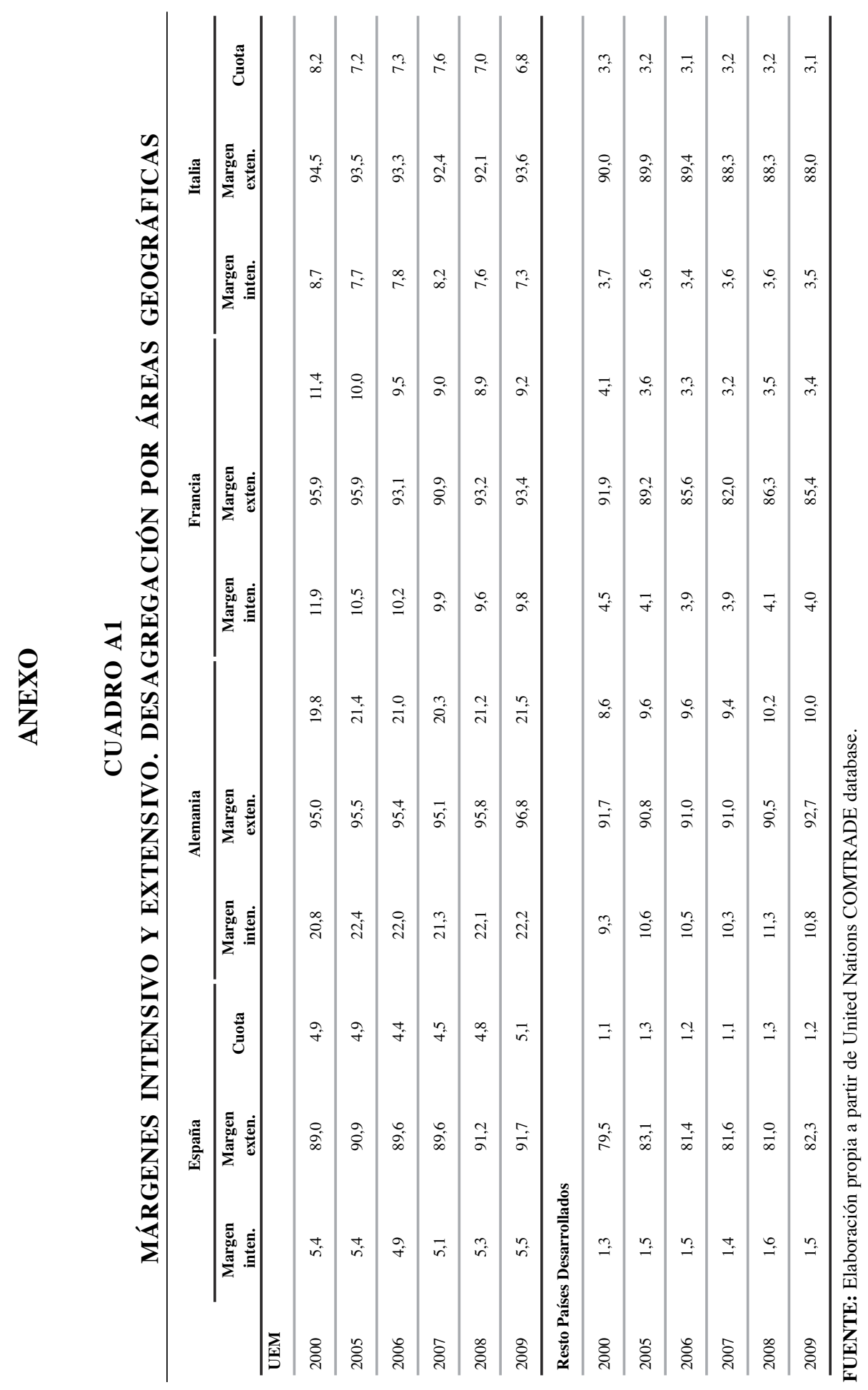




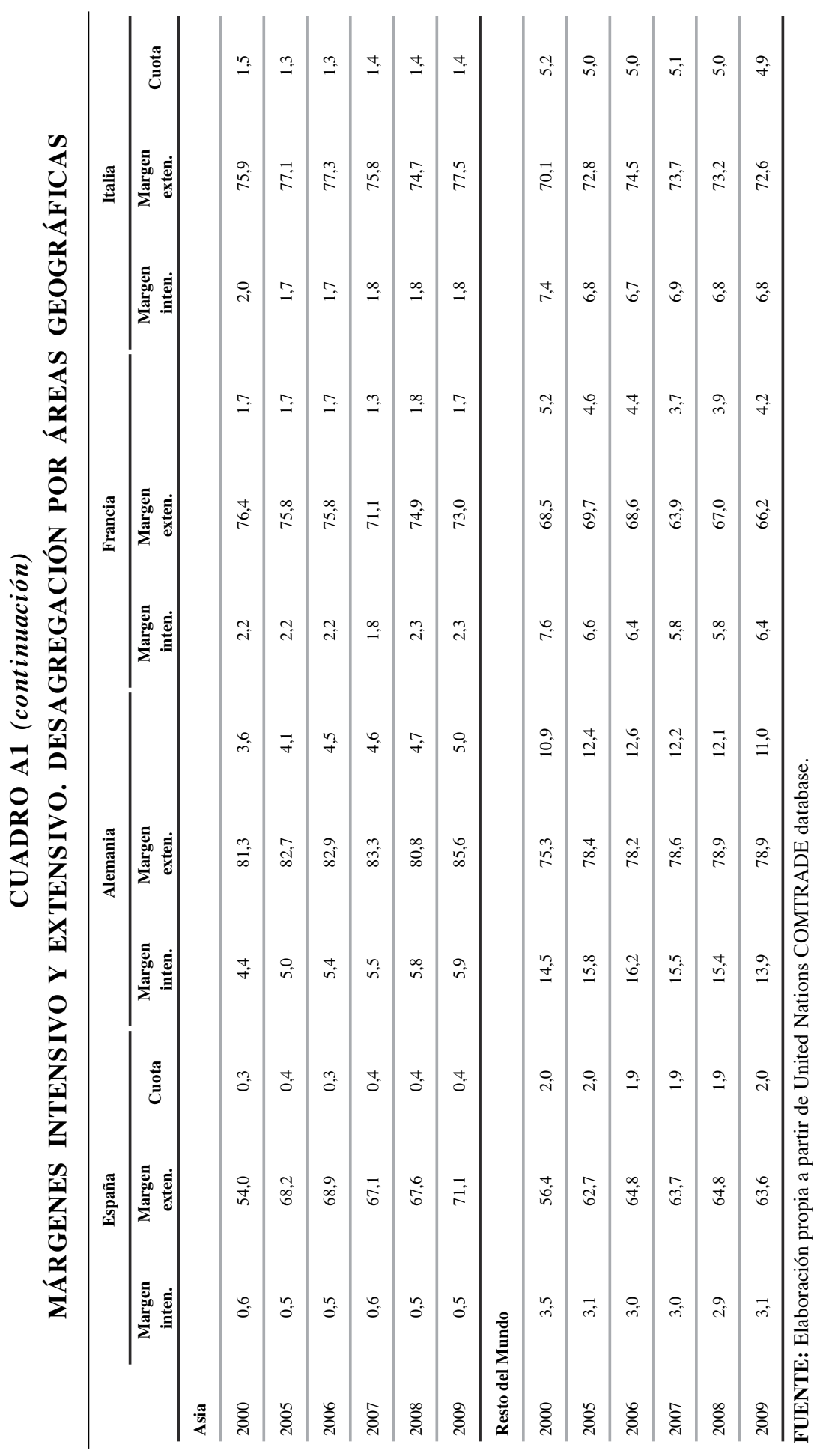




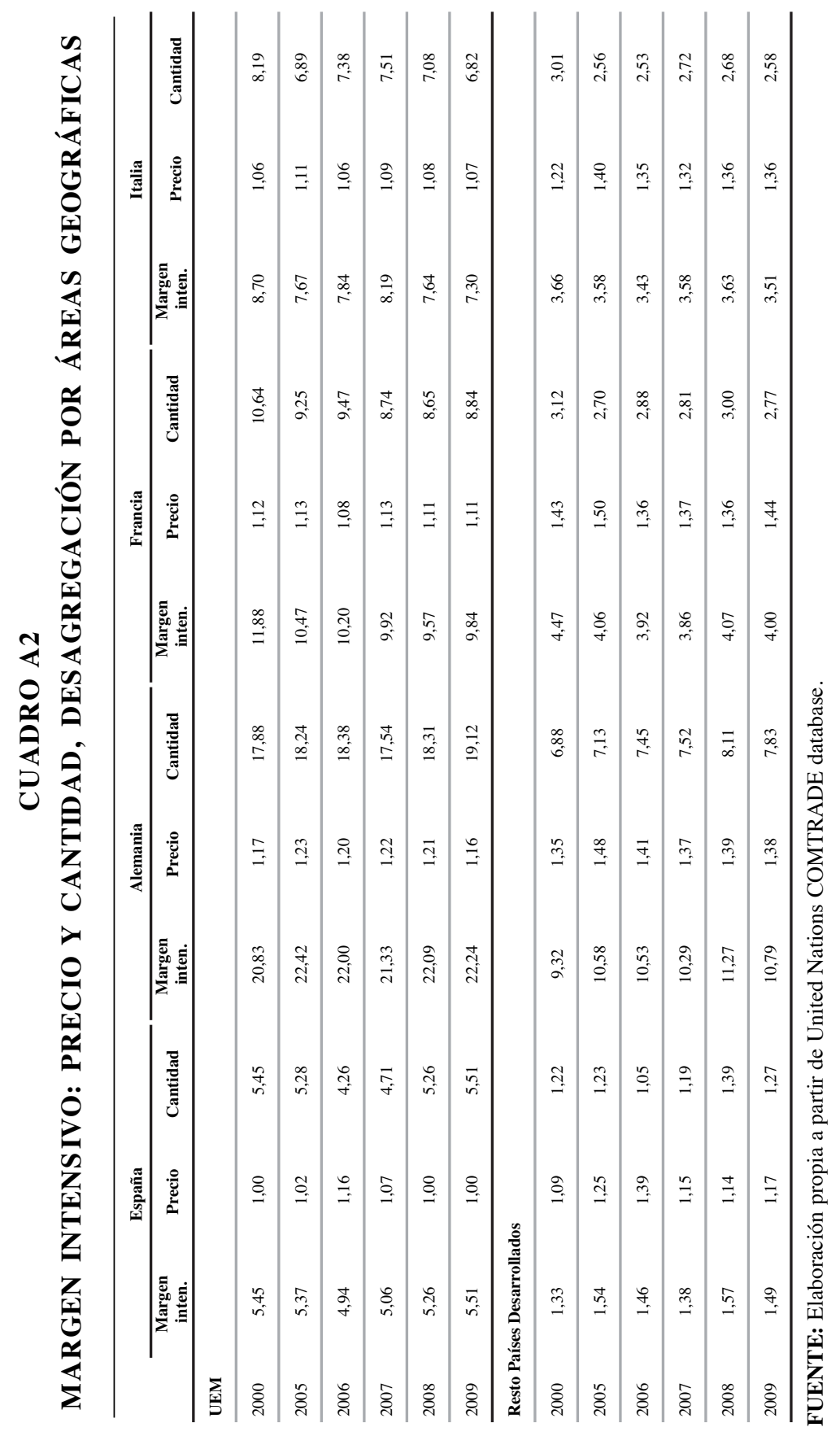




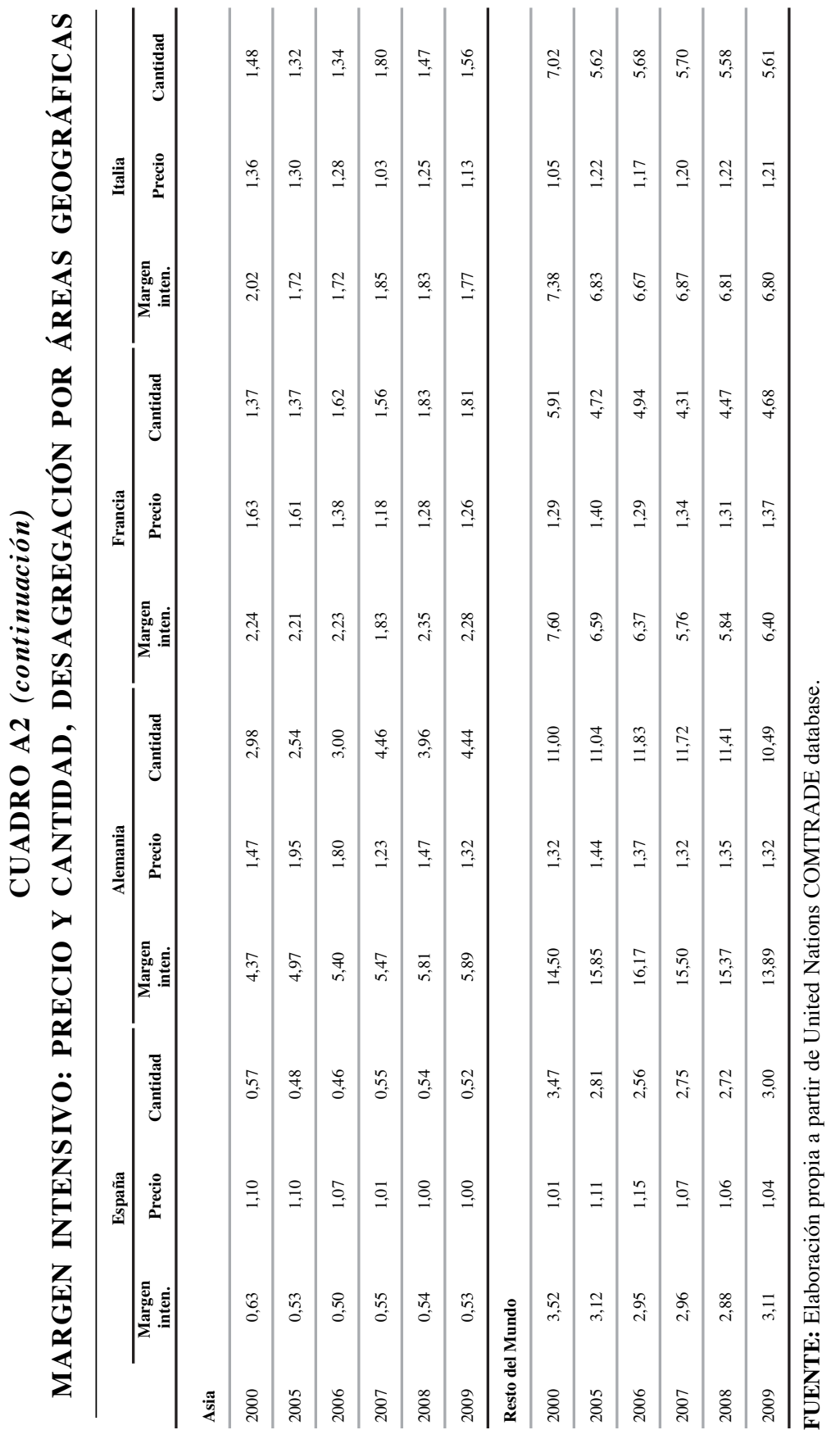

